\title{
BLASCO IBÁÑEZ Y LA CRISIS COLONIAL DEL 98
}

\section{BLASCO IBÁÑEZ AND THE COLONIAL CRISIS OF 98}

\section{AUTOR}

Francisco Marín Calahorro

Doctor en Ciencias de la Información por la Universidad Complutense de Madrid, Licenciado en Derecho por la UNED, diplomado en Derecho y Técnica Policial y especialista en Comunicación Social por la Universidad Complutense de Madrid (España)

franciscomarin@hotmail.com

\section{RESUMEN}

Vicente Blasco Ibáñez escribe sobre los acontecimientos que se sucedieron durante la guerra colonial. Su vehículo principal de expresión fue el diario "El Pueblo" durante el período comprendido entre 1895 y 1898. En sus artículos conjuga la crítica política y social hacia tres direcciones. La primera centrándose en la parte más dolorosa del conflicto, la marcha de los soldados a Cuba y su regreso enfermos; la segunda criticando los festejos que se realizan en España mientras se sucede la guerra, dejando ver la despreocupación del pueblo español hacia ella; y la tercera, donde denuncia al gobierno de aceptar una guerra contra los Estados Unidos imposible de ganar.

\section{PALABRAS CLAVE}

Crisis colonial - Blasco Ibáñez - periódico El Pueblo 


\section{ABSTRACT}

Vicente Blasco Ibanez writes about events that happened during the colonial war. His main vehicle of expression was the newspaper "The People" during the period between 1895 and 1898. In his articles combines political and social criticism in three directions. The first focusing on the most painful part of the conflict, the departure of the soldiers returning to Cuba and sick the second criticizing the celebrations taking place in Spain while the war happens, showing the carelessness of the Spanish people to her, and the third, where he denounces the government accept a U.S. war unwinnable.

\section{KEY WORDS}

Colonial crisis - Blasco I báñez - J ournal El Pueblo

\section{ÍNDICE}

1. Introducción.

2. Blasco Ibáñez y la expresión.

3. Conclusiones.

4. Bibliografía.

\section{Introducción.}

Vicente Blasco I báñez escribe sobre la crisis colonial desde su perspectiva política de republicano a ultranza y desde su postura personal de defensor del pobre y del desheredado. 


\section{Blasco Ibáñez y la expresión.}

Su vehículo principal de expresión, aunque escribe en diversos periódicos, será el periódico El Pueblo, "diario republicano de la mañana", que funda en Valencia el 12 de noviembre de 1894, y donde, durante el período 1895-1898, publica cerca de mil artículos.

Sus escritos sobre la guerra colonial conjugan la crítica política y social, esencialmente en tres direcciones. La primera dando la visión más dolorosa del conflicto, la marcha de los soldados a Cuba y su regreso enfermos, heridos y depauperados; la segunda, criticando la aparente despreocupación del pueblo español que se divierte asistiendo al teatro 0 a los toros, a las denominadas funciones o corridas patrióticas, mientras se aproxima una irremediable derrota; y, la tercera, denunciando al gobierno por haber aceptado una guerra, con los Estados Unidos, imposible de ganar.

En la primera dirección pueden servir de modelo tres artículos. Uno corresponde al 9 de marzo de 1895, apenas dos semanas después del inicio de la insurrección, titulado "El rebaño gris", refiriéndose al embarque de soldados en el puerto de Valencia.

"Un rebaño gris que, mansamente guiado por los pastores tristes y desalentados, avanzaba sobre los embreados maderos, subiendo la escala para desaparecer en las entrañas del transatlántico. ¡Viva la Patria! Hace falta carne humana en los hospitales; las fiebres antillanas, el feroz vómito negro, están hambrientos de víctimas, y allá va rumbo a las Antillas nuestra juventud robusta, arrancada al trabajo de los campos, a la industria de las ciudades, para caer exánime en la manigua o en el lecho caliente y apestado aún por el último moribundo, llamando en vano a la madre separada de ellos por miles de leguas". 
Aprovecha también para denunciar, lo que considera gran injusticia social, la circunstancia de que sólo los que no posean seis mil reales, que vale la exención del servicio militar, sean los que vayan a la guerra. Cuestión que reiterará, el 5 de septiembre de 1896, bajo el título "¡Que vayan todos: pobres y ricos!".

En defensa del pobre, del desheredado, saca a la luz una información, el 4 de agosto de 1896, que presenta bajo el titular "El premio del soldado" y expone la lamentable situación de algunas familias de soldados que combaten en Cuba. Así lo resumen como una novela de sufrimientos, de miserias, de vergonzoso abandono:

"La noticia ha resbalado sobre la indiferencia pública sin dejar huella alguna; $y$, sin embargo, es de las que deshonran a una nación. Iban por las calles de Barcelona dos niños haraposos con el lloriqueo del hambre contrauéndoles el rostro, las tiernas manecitas apretándose convulsivamente y el paso vacilante, propio del infeliz predestinado que apenas aprende a andar se tambalea con el mareo de la anemia."

Los agentes de la autoridad, siempre prontos para echar mano al que va por las calles miserables y abandonadas, detuvieron a los dos niños, que no supieron contestar a sus preguntas.

Los registraron y en el bolsillo de uno de ellos encontraron un papel que decía así:

"Nuestro padre, Higinio Palacios, de treinta años de edad, pelea en Cuba por la integridad del territorio; nuestra desolada madre, en el colmo de la miseria y próxima a dar a luz, ha ingresado en el hospital. Carecemos de alimentos y sólo esperamos la protección del cielo y el amparo de la Casa de Misericordia". 
El relato del regreso de los buques de Cuba con soldados enfermos o heridos, cierra esta primera parte de su visión personal sobre la guerra. Titula, el 21 de septiembre de 1897, "Carne para Tiburones" y comenta que había muchos de aquellos que morían en el viaje de vuelta y ser convertían en alimento de tiburones. Recoge la llegada a la península del buque Isla de Panay, que, en una sola expedición había perdido ciento veinte hombres de trescientos sesenta y cuatro que salieron de la Gran Antilla:

"Salió de Cuba con "cargamento" de soldados enfermos, y cómo estarían éstos, que a los dos días tuvo el capitán que dejar cincuenta de ellos en Puerto Rico.

Siguió el viaje. Antes de llegar a La Coruá, en once días murieron isesenta y cuatro soldados!, sesenta y cuatro cadáveres que, envueltos en sudario, atados a una tabla y con una bola en los pies, fueron arrojados al mar entre las bandas de tiburones que seguían al buque guiados por su excelente olfato, estremeciéndose de gula como el hambriento ante una mesa lujosamente servida.

Al llegar el buque al puerto, el primero que tuvo que subir a bordo fue el cura para administrar los últimos consuelos de la religión; mientras que los que aún conservaban un soplo de vida desembarcaban bajo lluvia torrencial; sin más abrigo que un trajecillo de lienzo, siguiendo con paso vacilante las camillas en que iban otros compañeros más débiles que ellos".

Blasco Ibáñez, que, como periodista, es un magnífico observador del acontecer diario, denuncia la aparente apatía y despreocupación de un importante sector de la sociedad ante la guerra, y el sufrimiento de los más afectados directamente por ella. Así, el 6 de agosto de 1897, titula "La nación se divierte". Escribe que, ante los 
españoles, se abre una "sima profunda y oscura" de débil corteza sobre la que "se mueve la nación con la mayor indiferencia" y proclama:

"Hace un año lo de Cuba aún preocupaba a la gente. Patriota había que no dormía noches enteras pensando si Maceo llegaría a pasar la trocha. Hoy todos nos hemos acostumbrado a que aquello dure, y las noticias de allá no se leen, por considerarlas precisas, pero sin interés, como el boletín de defunciones ocurridas el día anterior en el ciudad.

Hace un año bramaba de coraje la nación y se encrespaba a cada petición injusta de los Estados Unidos. Hoy a todos nos tiene sin cuidado lo que en aquel país digan o hagan contra nosotros. Nos desahogamos llamándoles "tocineros"... y después tan frescos".

Será éste el segundo eje de su crítica, que se incrementará cuando, una vez declarada la guerra con los Estados Unidos, se promocionen las funciones teatrales y corridas de toros calificadas como "patrióticas" para aportar fondos de ayuda al esfuerzo de guerra. De ahí que escriba el 16 de mayo de 1898, con un deje entre irónico, sarcástico y dolorido, su artículo "Siga la fiesta". Con su habitual estilo recurre a la pregunta retórica, que haría un yankee si el jueves, fecha de referencia, se hubiese paseado por Madrid: "¿Pero es esta nación la que sostiene una guerra con una nación poderosa y dos guerras civiles?..." y a continuación describe el panorama que se contemplaba en las calles de la capital de España dos semanas después de la derrota de Cavite:

"La alegría de vivir, la ruidosa carcajada de la dicha satisfecha, el anhelo de gozas, flores y vistosos trajes, uniformes y lucientes arreos, esto es lo que se veía el jueves en las calles de Madrid." 
Y este pueblo, núcleo de España, que aún no se ha dado cuenta exacta de la catástrofe de Cavite; estos descendientes de los que murieron el 2 de mayo como rebeldes de la legalidad y héroes de la patria, iban a los toros, a la "corrida patriótica", como si pudiera haber alarde de patriotismo en el monótono espectáculo de ver matar diez toros; como si se prestase un gran servicio a la patria pasando toda una tarde con las posaderas incrustadas en el duro banco del tendido aplaudiendo a los matadores y deseando el exterminio de los Estados Unidos entre trago y trago de manzanilla".

Sigue relatando la visión festiva de Madrid, cuyo pueblo parece ajeno a lo que ocurre y termina abundando en la crítica y, presentando a modo de epitafio lo que, para él, es la visión agónica de la derrota de Cavite:

"La época no puede ser más oportuna. Por esto somos el primer pueblo del mundo, por eso alcanzaremos triunfos nunca vistos por la historia; porque el patriotismo es aquí mucha marcha de Cádiz y ¡mueras los yankees! que están a tres mil leguas de distancia.

Y que rabien y lloren si quieren lo que el jueves, ante la arena de la plaza tinta en sangre de toro, pensaban en aquella otra arena de las playas de Cavite sembrada de miembros partidos, de troncos palpitantes, de cabezas hechas pedazos, cuyas bocas azuladas por la muerte no hablarán más el enérgico lenguaje de España; lo que ante el desfile de brillantes colores veían con los ojos de la imaginación la bandera española consumiéndose como la mariposa de rojo y oro entre las llamas de los buques que se hundieron en las aguas ennegrecidas por el humo de la batalla; lo que al escuchar el estallido de las salvas de aplausos dedicadas a los lances del espectáculo, creían que llegaba hasta ellos el eco de los inútiles estampidos de los cañones españoles vomitando con el ansia de la desesperación una muerto que no llegó al enemigo, mientras que 
éste, con la fría crueldad del carnicero, fue cebándose sin misericordia en el heroísmo sin laurel, en el martirio estéril".

El tercer eje de sus escritos construye una crítica permanente al gobierno por ir a una guerra imposible de ganar. Responsabilidad que, en su perfil de republicano convencido, suele repercutir hacia el régimen monárquico. Blasco Ibáñez percibe la proximidad de la guerra con los Estados Unidos y la anticipa tres semanas antes de que estalle. De ahí que, el 3 de abril de 1898, titule "Lo del día.- La guerra" y afirme:

"No hemos buscado nosotros la guerra; antes bien, nuestra nación, que siempre ha pecado de belicosa y agresiva, se ha mostrado en esta ocasión pacienzuda y prudente.

Hemos pagado indemnizaciones injustas que equivalían a verdaderos robos; hemos consentido un apoyo descarado e insolente a los enemigos de España: al recibir una bofetada hemos presentado la otra mejilla; pero son tantos ya los golpes, que nuestra patria no puede seguir por más tiempo en esta actitud, que si hasta ahora revelaba prudencia, en adelante denunciaría cobardía".

Sin embargo, aunque señale que España ha sido víctima de las exigencias de los norteamericanos, se vuelve contra el sistema, que no comparte, para acusar con su pluma.

"Bien sabemos dónde reside la culpa de todo lo que ocurre. En el régimen monárquico y en ese espíritu de reacción que no solamente ha envilecido la Península, sino que ha influido poderosamente en la suerte de las colonias. Triste privilegio de la restauración ha sido hacer todas las cosas fuera de tiempo y oportunidad". 
Consumada la derrota, con la pérdida de las escuadras españolas en Cavite y Santiago de Cuba, y capituladas las tripas que defendían esta última ciudad, Blasco Ibáñez escribe, el 22 de junio de 1898, "La paz deshonrosa". Anuncia que el gobierno busca la paz a todo trance y anticipa que "una paz buscada en las presentes circunstancias sólo puede conseguirse entregando al enemigo Cuba, Puerto Rico y Filipinas; esta vergüenza, este despojo irritante es lo que los monárquicos proporcionan a España". Pero no se conforma y apostilla:

"Su carencia de todo patriotismo resulta indiscutible. ¿Sabían hace dos meses que España carece de elementos para sostener una lucha con los Estados Unidos? Pues debieron evitar la guerra por amor a España; en vez de acelerarla con el fin de halagar los sentimientos patrióticos y dar cierta popularidad a la monarquía. Resultado infame la inconsecuencia de los gobernantes monárquicos. Cuando se trataba de combatir cubanos y filipinos, que aunque rebeldes al fin son españoles y hablan nuestra lengua, entonces mucho desplante enérgico y rotundas negativas de arreglar por medio de la libertad lo que inútilmente ha querido resolverse por las armas; y ahora que hay que combatir a verdaderos enemigos, a extranjeros hostiles a nuestra raza y nuestras costumbres, mucho miedo, mucha cobardía e inicuos deseos de terminar cuanto antes el conflicto, aun a costa de la desmembración de la patria".

Su punto y final a la guerra colonial lo pondrá el 11 de febrero de 1899. Firmada la Paz de París el 10 de diciembre anterior, España renunció a la soberanía sobre sus territorios en las Antillas y el Pacífico, excepto las islas Carolinias, Marianas y Palaos, que serían vendidas a Alemania coincidiendo prácticamente con la fecha del artículo de Vicente Blasco I báñez. El título, "la única responsable", es significativo; en él, va a hacer una breve disección de la guerra y buscará responsabilidades. Recurrirá, como en otras ocasiones, a las preguntas retóricas, que el autor del relato contestará razonablemente, para llegar a la conclusión que, según su talante republicano, no 
será otra que la única responsable de los resultados de la guerra es la monarquía. Sus planteamientos van directos al centro de la cuestión y señala:

"¿De quien es la culpa? Esto es lo que el Gobierno de Sagasta ha tenido buen cuidado de ocultar y lo que está en la conciencia de todo el país.

Mienten esos gobernantes que han hablado en nombre de la patria para justificar sus desaciertos; mienten los que han pretendido extender sus culpas a toda la nación, haciendo responsables al soldado que no ha hecho más que obedecer o al ciudadano que no ha hecho más que pagar tributos o ceder la sangre sus hijos; en este conflicto nacional no se ha pensado en la ptria sino en las instituciones; no ha sido dirigida la empresa de la conservación nacional por desinteresados patriotas, cino por egoístas monárquicos".

"¿De quien ha sido la culpa? No ha hecho la nación más que cumplir cuantos sacrificios se le han exigido. Los soldados han sabido batirse siempre que no le han dado órdenes en sentido contrario. La masa popular ha sufrido con resignación patriótica la absurda ley de castas, de pobres y ricos, que hace gravitar sobre ella el peso de la defensa nacional. Nadie ha puesto su egoísmo por encima de los intereses de la ptria. Únicamente la monarquía y sus hombres, por seguir en pie, no han vacilado en enterrar la nación.

La idea de la necesidad de la regeneración nacional la presenta Blasco Ibáñez al finalizar este artículo. Como otros intelectuales del momento la cree necesaria. Sin embargo, la propone desde la ruptura con el régimen monárquico. De ahí que aproveche la coincidencia de la fecha de publicación, 11 de febrero, con el 26 
aniversario de la proclamación de la $1^{\text {a }}$ República española $y$, fiel a sus principios, afirme: "Hoy la República ya no es solución política, sino necesidad nacional; es la dignificación de la patria, el único Jordán en que puede España purificarse".

Es su punto final a la guerra colonial. En sus artículos sobre ella, el periodista Blasco Ibáñez no puede evitar que aflore su personalidad política. Escribió en otros periódicos, pero El Pueblo fue el órgano ideológico de su concepción del republicanismo federal. Le sirvió, para manifestar su militancia política, que le llevará a ser elegido diputado republicano a las Cortes de 1898, sin dejar de hacer un análisis preciso de la sociedad española del momento.

\section{Conclusiones.}

Blasco I báñez es un escritor, comprometido con sus ideas, que le llevarán a la cárcel y el exilio. Utilizó El Pueblo como instrumento de difusión de su modelo conceptual republicano y para concienciar políticamente a sus correligionarios. Más tarde, cuando se aparta de la acción directa, serán sus novelas el medio para presentar los problemas sociales de hace un siglo.

\section{Bibliografía.}

IBAÑÉZ, Blasco. Viajero. Valencia, 1998.

IBAÑ́́Z, Blasco. Viva la Republica. Madrid, 1893. 